\title{
Distinct Roles of Hippocampal De Novo Protein Synthesis and Actin Rearrangement in Extinction of Contextual Fear
}

\author{
André Fischer, Farahnaz Sananbenesi, Christina Schrick, Joachim Spiess, and Jelena Radulovic \\ Laboratory on Cell Biological Mechanisms of Memory, Department of Molecular Neuroendocrinology, Max Planck Institute for Experimental Medicine, \\ 37075 Goettingen, Germany
}

It is believed that de novo protein synthesis is fundamentally linked to synaptic changes in neuronal circuits involved in acquisition and extinction of conditioned responses. Recent studies show that neuronal plasticity may be also altered by cytoskeletal rearrangement independently of protein synthesis. We investigated the role of these processes in the hippocampus during acquisition and extinction of context-dependent conditioned fear in mice. Intrahippocampal injections of the protein synthesis inhibitors anisomycin and puromycin, or of the actin rearrangement inhibitors cytochalasin D and latrunculin A, prevented the acquisition of context-dependent fear. Unexpectedly, anisomycin and puromycin enhanced extinction without erasing the fear memory. In contrast, cytochalasin $\mathrm{D}$ and latrunculin A prevented extinction of context-dependent freezing. On the basis of these findings, it is suggested that certain hippocampal mechanisms mediating extinction of conditioned contextual fear are inhibited by protein synthesis and involve actin rearrangement. Such mechanisms might predominantly elicit modifications of hippocampal circuits that store the conditioning memory.

Key words: extinction; fear conditioning; hippocampus; actin rearrangement; protein synthesis; mice

\section{Introduction}

Single exposure of rodents to a conditioned stimulus (CS) such as novel context followed by an unconditioned stimulus (US) such as footshock elicits acquisition of conditioned fear. It is assumed that an "excitatory" association between the CS and the US triggers a conditioned response (CR) such as freezing behavior when the animals are re-exposed to the CS (Blanchard and Blanchard, 1969). However, if the CS is presented without the US (nonreinforced trials), the CR declines, a phenomenon termed "extinction" (Pavlov, 1927; Falls and Davis, 1995; Myers and Davis, 2002). It is thought that extinction represents a learning process based on the formation of new "inhibitory" associations between the CS and the US that prevent the occurrence of the CR (Konorski, 1948). Importantly, extinction does not result in loss of the fear memory, as indicated by reinstatement, renewal, and spontaneous recovery of the CR after defined experimental manipulations (Rescorla and Heth, 1975; Bouton, 1993).

It is well documented that acquisition of the CR depends on de novo protein synthesis (Davis and Squire, 1984). An involvement of protein synthesis in extinction of the CR has been demonstrated recently (Berman and Dudai, 2001; Vianna et al., 2001; Lin et al., 2003; Pedreira and Maldonado, 2003). However, protein synthesis-dependent extinction was observed only in trials that led to reduced CR after one nonreinforced session. Such

\footnotetext{
Received Sept. 22, 2003; revised Dec. 17, 2003; accepted Dec. 19, 2003.

This research was supported by the Max Planck Society. We thankC. Todorovic and M. Radulovic for comments on this manuscript.

Correspondence should be addressed to Jelena Radulovic, Laboratory on Cell Biological Mechanisms of Memory, Department of Molecular Neuroendocrinology, Max Planck Institute for Experimental Medicine, Hermann-Rein Strasse 3, 37075 Goettingen, Germany. E-mail: radulovic@mail.em.mpg.de.

D01:10.1523/JNEUROSCI.5112-03.2004

Copyright $\odot 2004$ Society for Neuroscience $\quad 0270-6474 / 04 / 241962-05 \$ 15.00 / 0$
}

rapid extinction may be elicited when the intensity of the conditioning protocol is mild or when the extinction session consists of long or multiple trials (Eisenberg et al., 2003; Pedreira and Maldonado, 2003).

Brief nonreinforced exposures to the CS appear to preferentially activate the excitatory associations acquired during conditioning (Eisenberg et al., 2003). Under those conditions, anisomycin, an inhibitor of protein synthesis, significantly reduces conditioned freezing (Nader et al., 2000; Debiec et al., 2002). It has been proposed that anisomycin disrupts the fear memory and that protein synthesis-dependent reconsolidation is essential for further storage of the reactivated memory (Nader et al., 2000). Alternatively, anisomycin might elicit performance or retrieval deficits (Millin et al., 2001). It should be taken into account, however, that brief nonreinforced exposures to the CS also lead to extinction over several daily trials (Bouton, 1993). On this basis, reduction of the CR by anisomycin could reflect enhanced extinction. Thus, extinction might additionally involve modifications of excitatory associations by mechanisms that differ from protein synthesis-dependent formation of new inhibitory associations. It was suggested that extinction of conditioned fear could be mediated by mechanisms that are independent of protein synthesis (Lattal and Abel, 2001) such as cytoskeletal rearrangement, a possibility that has not been tested so far. Notably, cytoskeletal rearrangement profoundly alters hippocampal plasticity independently of protein synthesis (Antonova et al., 2001) and elicits morphological changes within activated hippocampal circuits (Rao and Craig, 2000). In the present study, we attempted to delineate the involvement of hippocampal protein synthesis and actin rearrangement in acquisition and extinction of contextdependent conditioned fear. 


\section{Materials and Methods}

Subjects. Eight-week-old male C57BL/6J mice (Centre d'Élevage Janvier, Le Genest-St-Isle, France) were individually housed and maintained as described previously (Radulovic et al., 1998). Experiments were performed in accordance with the European Council Directive (86/609/ EEC) with the permission of the Animal Protection Law enforced by the District Government of Braunschweig, Germany.

Conditioning and extinction of context-dependent fear. Fear conditioning consisted of a single exposure to context $(3 \mathrm{~min})$ followed by a tone (30 sec, $10 \mathrm{kHz}, 75 \mathrm{~dB}$ sound pressure level) and footshock ( $2 \mathrm{sec}, 0.7 \mathrm{~mA}$, constant current) as described previously (Radulovic et al., 1998). Context-dependent freezing was measured $24 \mathrm{hr}$ later every $10 \mathrm{sec}$ for 180 sec by two observers unaware of the experimental conditions and expressed as a percentage of total number of observations. In indicated experiments, tone-dependent freezing was evaluated in an identical manner (over a $3 \mathrm{~min}$ time period) in a different context. The extinction trials were performed in $24 \mathrm{hr}$ intervals and consisted of nonreinforced exposures to context $(3 \mathrm{~min})$ and tone $(30 \mathrm{sec})$.

Reminder. An immediate footshock ( $2 \mathrm{sec}, 0.7 \mathrm{~mA}$, constant current) presented in a novel context served as a reminder. This procedure did not support fear conditioning in our experiments. The reminder shock was always applied $24 \mathrm{hr}$ after the last memory test, and freezing behavior was determined $24 \mathrm{hr}$ later by re-exposing the mice to the conditioning context.

Cannulation and injections. Double cannulas were placed into the dorsal hippocampus [anteroposterior, $1.5 \mathrm{~mm}$; lateral, $1 \mathrm{~mm}$; depth, $2 \mathrm{~mm}$ ] as described previously (Radulovic et al., 1998). The guide and injection cannulas were 26 and 28 gauge, respectively. Anisomycin and puromycin (Sigma, St. Louis, MO) were dissolved in $1 \mathrm{M} \mathrm{HCl}$, diluted in artificial CSF (aCSF), and adjusted to $\mathrm{pH} 7.4$ with $\mathrm{NaOH}$. Cytochalasin D (Biomol, Plymouth Meeting, PA) and latrunculin A (Sigma) were dissolved in 2\% DMSO in aCSF. The inhibitors were delivered bilaterally $(0.25 \mu \mathrm{l} /$ side $)$ over a $15 \mathrm{sec}$ period before or after training and testing as indicated. The cannula position was determined for each mouse by methylene blue injection after the end of experiments, and only data obtained from mice with correctly inserted cannulas were analyzed.

Immunoblot. To assess the effects of the inhibitors on de novo protein synthesis and activity of stress-activated and mitogen-activated kinases, the levels of the cFos protein and the levels of phosphorylated cJun ( $\mathrm{p}$ cJun) and phosphorylated ATF2 (p-ATF2) were determined $1 \mathrm{hr}$ after post-training injection of each inhibitor. cFos production was measured because this protein is newly synthesized after fear conditioning (Radulovic et al., 1998). p-cJun and p-ATF2, the main downstream targets of stress-activated and mitogen-activated kinases, were monitored to evaluate other cellular effects of anisomycin (Torocsik and Szeberenyi, 2000) and possibly other inhibitors in vivo. The dorsal hippocampi were dissected in a 1\% SDS loading buffer and boiled for $5 \mathrm{~min}$. After $10 \mathrm{~min}$ of sonication, $20 \mu \mathrm{g}$ of each extract were separated by SDS-PAGE, transferred to polyvinylidene difluoride membranes, and immunostained with antibodies recognizing cFos p-cJun, cJun, p-ATF2, and ATF2. All antibodies were purchased from Santa Cruz Biotechnology (Santa Cruz, CA) and diluted 1:1000. The levels of p-cJun and p-ATF2 were first normalized to the amounts of total cJun and ATF2, respectively, and their relative changes were subsequently compared among experimental groups.

Statistical analysis. Statistically significant differences were determined by two-way ANOVA (test and treatment) followed by Dunnet's test for post hoc comparisons, one-way ANOVA, or Student's $t$ test. The results are presented as mean $\pm \mathrm{SE}$.

\section{Results}

Hippocampal de novo protein synthesis prevents extinction without affecting reconsolidation of context-dependent conditioned fear

C57BL/6J mice were injected intrahippocampally with different doses of anisomycin immediately after conditioning. A dose of 50 $\mu \mathrm{g}$ of anisomycin per hippocampus significantly decreased freezing $\left(t_{(1,16)}=6.375 ; p<0.001\right)$ when compared with the vehicle
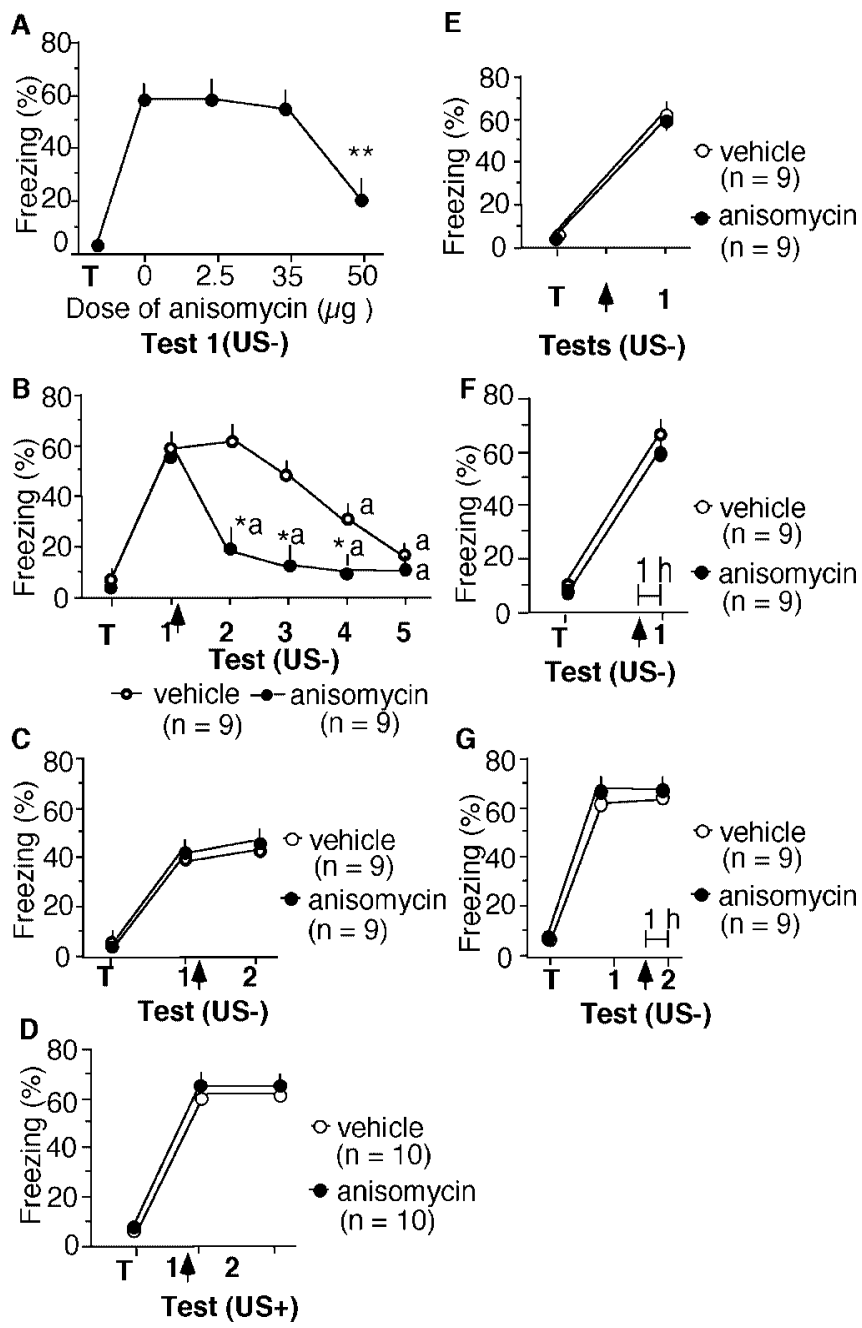

Figure 1. Inhibition of de novo protein synthesis impairs conditioned freezing after extinction trials without affecting retrieval. $A$, Dose-dependent impairment consolidation of contextual fear by anisomycin. There were nine mice per group. $B$, Anisomycin (50 $\mu \mathrm{g}$, i.h.) injected after the first nonreinforced trial (US-) also decreased context-dependent freezing without affecting tone-dependent freezing ( $C$ ) when compared with the vehicle group. $D$, Anisomycin injected after a reinforced trial did not affect freezing. $E$, Anisomycin injected without memory reactivation did not affect freezing. $F$, Anisomycin did not affect freezing when it was injected intrahippocampally $1 \mathrm{hr}$ before the first or second $(G)$ memory test. Statistically significant differences: ${ }^{*} p<0.01,{ }^{* *} p<0.001$ versus vehicle control; ${ }^{a} p<0.01$ versus test 1 . Arrow indicates the anisomycin or vehicle injection. T, Training.

control, indicating impaired memory consolidation of contextdependent conditioned fear (Fig. $1 A$ ).

The same dose of anisomycin was subsequently applied after extinction trials. Mice trained in the fear-conditioning paradigm were re-exposed to the conditioned stimuli without presentation of footshock (US-). Immediately after the first nonreinforced trial (test 1), mice were injected intrahippocampally with anisomycin or vehicle. In the vehicle group, freezing significantly declined over five trials $\left(F_{(1,40)}=9.220 ; p<0.01\right)$, reflecting extinction (Fig. $1 B$ ). Freezing of anisomycin-injected mice was significantly reduced during test 2 compared with the vehicle group $\left(t_{(1,16)}=5.299 ; p<0.01\right)$ and remained low during tests 3-5 (Fig. $1 B$ ). Thus, a single injection of anisomycin after the first nonreinforced test persistently reduced context-dependent freezing. Tone-dependent freezing (Fig. $1 C$ ) did not differ significantly between groups $\left(t_{(1,16)}=0.375 ; p=0.709\right)$. This finding is consistent with the predominant involvement of the hippocam- 
pus in context-dependent versus tone-dependent fear conditioning (Kim and Fanselow, 1992). To test the specificity of the effect of anisomycin observed after nonreinforced trials, mice were trained and re-exposed to reinforced memory tests (US + ) consisting of presentation of the conditioning context and tone, terminating with footshock. Injection of anisomycin did not decrease freezing (Fig. 1D) compared with the previous memory test or the vehicle group $\left(F_{(1,36)}=0.408 ; p=0.5269\right)$. Thus, anisomycin reduced freezing only if memory reactivation consisted of an extinction trial.

We injected additional mice intrahippocampally with anisomycin $24 \mathrm{hr}$ after training without exposing them to a nonreinforced memory test. In the absence of contextual re-exposure, anisomycin did not affect freezing $\left(t_{(1,16)}=1.799 ; p<0.2095\right)$ (Fig. $1 E$ ). Anisomycin injected intrahippocampally $1 \mathrm{hr}$ before the first (Fig. $1 F$ ) or second (Fig. $1 G$ ) memory test did not affect freezing (test $1, t_{(1,16)}=0.004, p<0.9485$; test $2, t_{(1,16)}=0.04$, $p<0.9522)$. These findings suggest that de novo protein synthesis is not required for retrieval of context-dependent fear.

To delineate whether the observed impairment of contextdependent freezing resulted from an effect on memory reconsolidation or extinction, control experiments were performed. Mice were trained and then exposed to the conditioned stimuli daily for 5 consecutive days. This procedure led to extinction (Fig. 2A). Subsequent exposure of these mice to a reminder shock resulted in reinstatement of freezing $\left(t_{(1,18)}=8.753 ; p<0.01\right)$. The finding that the reminder did not elicit freezing in mice without previous training (Fig. $2 \mathrm{~A}$ ) demonstrated that the reminder procedure itself did not support fear conditioning. Mice were injected with anisomycin (50 $\mu$ g, i.h.) or puromycin ( $25 \mu \mathrm{g}$, i.h.) immediately after training. The later protein synthesis inhibitor was included to control for nonspecific effects of anisomycin on stress and mitogen-activated kinase pathways (Edwards and $\mathrm{Ma}-$ hadevan, 1992). Accordingly, although both inhibitors significantly reduced the production of the cFos protein, the levels of p-cJun and p-ATF2 were elevated in anisomycin-injected mice but not in puromycin-injected mice (Fig. $2 B$ ). Mice injected with either inhibitor (Fig. 2C) froze significantly less after the reminder shock than did their vehicle controls $\left(F_{(2,26)}=9.732 ; p<\right.$ $0.01)$. In contrast, mice injected after the first extinction trial reinstated the freezing response (Fig. $2 D$ ) that reached levels similar to the vehicle control $\left(F_{(2,25)}=0.985 ; p=0.431\right)$. The reminder procedure did not elicit generalized fear, as revealed by significantly less freezing in vehicle-, anisomycin-, and puromycin-injected mice in a novel context $\left(F_{(5,48)}=11.224\right.$; $p<$ 0.01 ) than in the conditioning context (Fig. $2 D)$. Reinstatement of freezing after post-test injection of anisomycin or puromycin (Fig. 2D) was similar to the reinstatement observed after extinction (Fig. $2 A$ ) and indicated that the stability of the original memory was not affected by inhibition of protein synthesis. Therefore, it was concluded that intrahippocampal inhibition of protein synthesis after the first nonreinforced trial significantly accelerated extinction without affecting reconsolidation of contextdependent fear memory.

\section{Hippocampal actin rearrangement is required for extinction of context-dependent fear}

Post-training injection of cytochalasin D (125 ng, i.h.) or latrunculin A (125 ng, i.h.), inhibitors of actin dynamics, did not significantly affect the levels of the cFos protein or the phosphorylation of cJun and ATF2 transcription factors at the doses used (Fig. 3A). Nevertheless, both inhibitors impaired freezing $\left(F_{(2,24)}=7.96 ; p<0.01\right)$ when compared with the vehicle control
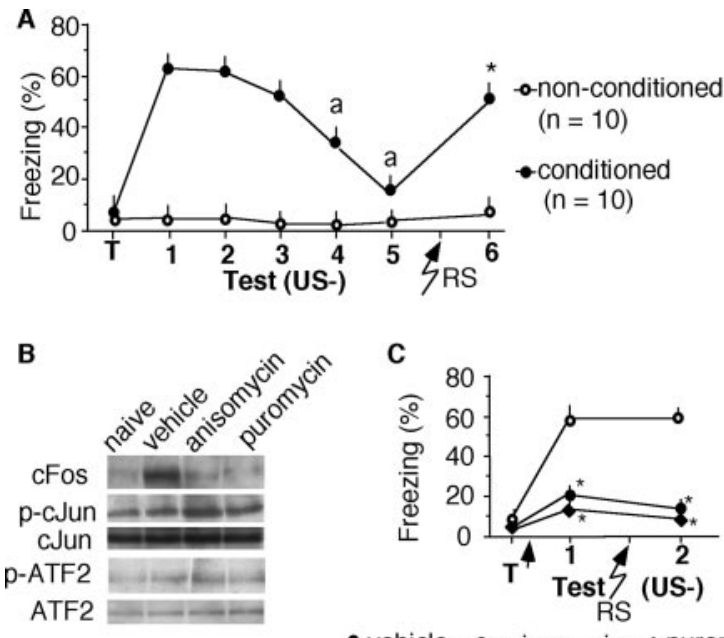

C
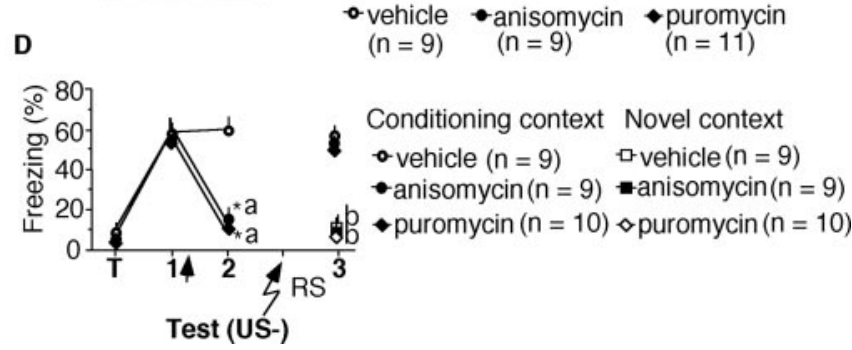

Figure 2. Inhibition of de novo protein synthesis after memory reactivation does not permanently erase the fear memory. $A$, Fear-conditioned mice exposed to a reminder shock $24 \mathrm{hr}$ after the last extinction trial reinstated freezing behavior. In contrast, nonconditioned mice did not show freezing after the reminder shock. $B$, Representative immunoblots demonstrating the biochemical effects of anisomycin and puromycin injected intrahippocampally immediately after training. Both inhibitors completely prevented the production of the cFos protein, as determined $1 \mathrm{hr}$ after training. In addition, anisomycin increased the level of $\mathrm{p}$-cuun [percentage increase (mean \pm SEM) vs vehicle, $212 \pm 28 \%$ ) and p-ATF2 (percentage increase vs vehicle, $57 \pm 11 \%$ ), whereas puromycin did not exert a significant effect. The experiment was replicated twice with three mice per group. C, Injection of anisomycin ( $50 \mu \mathrm{g}$, i.h.) or puromycin (25 $\mu \mathrm{g}$, i.h.) after training prevented the consolidation of contextual fear. A reminder shock failed to reinstate freezing behavior in this group. $D, A$ reminder shock reinstated freezing behavior of mice injected with anisomycin or puromycin after the first nonreinforced memory test. Statistical differences: ${ }^{*} p<0.01$ versus vehicle control; ${ }^{a} p<0.01$ versus test $1 ;{ }^{b} p<0.01$ versus conditioning context. RS, Reminder shock.

(Fig. 3B). This finding shows that actin rearrangement was involved in memory consolidation of context-dependent conditioned freezing independently of de novo protein synthesis. Additional mice were trained and subsequently exposed to nonreinforced extinction trials. Cytochalasin D or latrunculin A were injected intrahippocampally immediately after each test. The freezing behavior of cytochalasin D- or latrunculin A-injected mice did not decline after repeated exposures, indicating that this treatment completely blocked extinction. Thus, freezing of mice injected intrahippocampally with cytochalasin D or latrunculin A was significantly higher $\left(F_{(2,144)}=17.889 ; p<\right.$ 0.001 ) compared with the vehicle-injected group (Fig. $3 C$ ). To test whether the inhibitors nonspecifically increased freezing, separate groups were injected intrahippocampally with either drug or vehicle immediately after memory tests 4 and 5. During these tests, mice exhibited extinction, as revealed by a significant decrease in freezing on test 4 when compared with test $1\left(F_{(3,32)}=\right.$ 11.263; $p<0.001)$. Application of cytochalasin D or latrunculin A after tests 4 and 5 did not increase freezing (Fig. 3D). Together, these results show that both memory consolidation and extinction of context-dependent freezing depend on actin rearrangement in the hippocampus. 
A

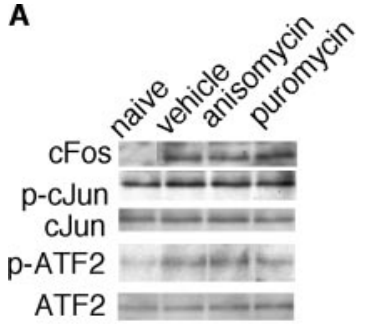

B

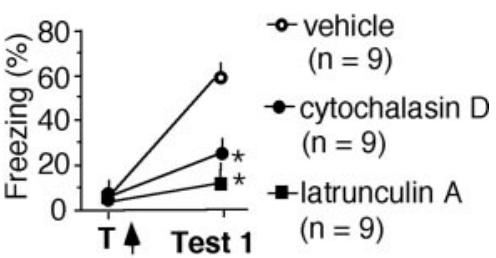

C

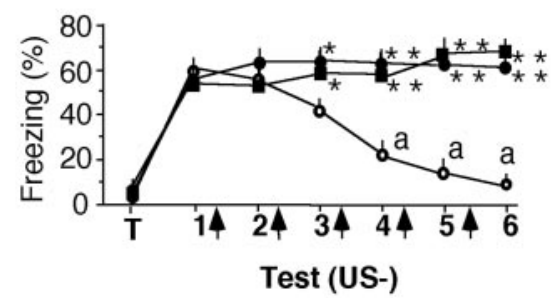

-o-vehicle $(n=9)$

- cytochalasin D $(n=9)$

-latrunculin A $(n=9)$

D

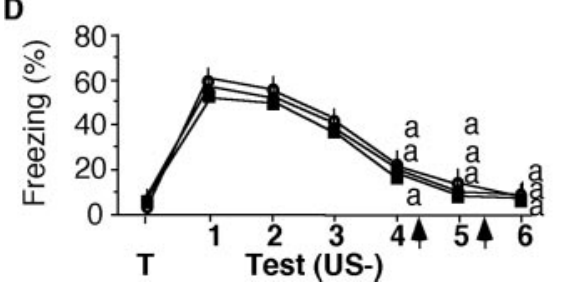

- - vehicle

$(n=9)$

- cytochalasin D

$(n=9)$

- -latrunculin A

$(n=9)$

Figure 3. Acquisition and extinction of context-dependent fear involve actin rearrangement. $A$, Cytochalasin D and latrunculin A (125 ng each per hippocampus) injected intrahippocampally immediately after training prevented the consolidation of context-dependent fear. $B$, Representative immunoblots demonstrating the biochemical effects of the inhibitors injected intrahippocampally immediately after training. The inhibitors did not affect the production of the cFos protein or the phosphorylation of cJun and ATF2 in hippocampal lysates prepared $1 \mathrm{hr}$ after training. The experiment was replicated twice with three mice per group. C, The same doses of cytochalasin D and latrunculin A injected intrahippocampally after each nonreinforced memory test prevented the extinction of context-dependent freezing (compared with the vehicle group). D, Cytochalasin D and latrunculin A injected intrahippocampally after extinction did not result in increased conditioned freezing. Statistical differences: ${ }^{*} p<0.01$, ${ }^{* *} p<$ 0.01 versus vehicle control; ${ }^{a} p<0.01$ versus test 1 .

\section{Discussion}

Consistent with previous observations (Davis and Squire, 1984), post-training injection of anisomycin or puromycin into the dorsal hippocampus significantly impaired acquisition of contextdependent fear. The amnestic effect was further documented by the inability of a reminder shock to reinstate conditioned freezing. Although both inhibitors prevented cFos production and memory formation, puromycin was effective at a lower dose than anisomycin, possibly because this inhibitor did not significantly trigger the stress-activated and mitogen-activated protein kinases.

Inhibition of hippocampal protein synthesis after the first extinction trial also reduced freezing, as observed previously (Debiec et al., 2002). Taking into account that reduction of conditioned responses rarely results from a loss of memory (Riccio and Richardson, 1984; Cahill et al., 2001), we considered that the effects observed in our study might reflect enhanced extinction. This possibility was supported by the ability of a reminder shock to reinstate conditioned freezing in mice injected with anisomycin or puromycin after the nonreinforced trial. Thus it was demonstrated that the doses of inhibitors used in these experiments did not prevent the formation of stable fear memory after its reactivation. As shown previously (Rescorla and Heth, 1975), reinstatement of conditioned freezing was also observed after extinction. On this basis, it was concluded that anisomycin and puromycin enhanced extinction and suggested that hippocampal mechanisms involving de novo protein synthesis reduced extinction in the paradigm used. It remains to be elucidated whether higher doses of the inhibitors might block extinction.

It may seem paradoxical that protein synthesis counteracting extinction is elicited during brief extinction trials. However, such a mechanism could prevent rapid extinction of conditioned freezing in situations in which the CS does not reliably predict absence of the US. Thus, extinction could occur when hippocampal protein synthesis decreases in response to the conditioning context. This possibility is consistent with the downregulation of immediate-early genes such as $c$-fos, egr-1, and $\operatorname{arc}$ (Radulovic et al., 1998; Malkani and Rosen, 2000; Kelly and Deadwyler, 2002) with short nonreinforced exposures to the conditioned stimuli.

It has been suggested that behavioral deficits might result from impaired retrieval of the fear memory or from the inability of the retrieved memory to trigger a fear response (Harris and Westbrook, 1998). The former view was supported in studies with passive avoidance, demonstrating that anisomycin may elicit deficits in the expression of conditioned responses that are transient (Vianna et al., 2001; Anokhin et al., 2002) or restricted to limited time periods after training (Milekic and Alberini, 2002), possibly by impairing retrieval. Inhibition of protein synthesis did not seem to interfere with retrieval during extinction of conditioned freezing, as indicated by the observation that anisomycin injected $1 \mathrm{hr}$ before testing, a time period when significant inhibition of protein synthesis was observed, did not affect freezing behavior. Furthermore, freezing was significantly reduced over three extinction trials after a single anisomycin injection (Fig. $1 B$ ), and this effect was not time-limited (Debiec et al., 2002). It is therefore likely that inhibition of protein synthesis in the hippocampus enhanced extinction by reducing the ability of the conditioning memory to elicit freezing behavior.

De novo protein synthesis leads to a persistent activation of a number of protein kinases, such as protein kinase C (Osten et al., 1996) that directly, or via downstream targets, significantly increase actin stability (He et al., 1997). Thus protein synthesis could alter actin rearrangement and retard extinction. In line with this view, inhibition of actin dynamics by cytochalasin D or latrunculin A completely prevented extinction of contextdependent freezing. Notably, the inhibitors were not effective when applied after extinction of conditioned freezing. This finding suggests that actin rearrangement might selectively modify the excitatory association activated before extinction. Reduced acquisition of context-dependent fear elicited by hippocampal inhibition of actin rearrangement is consistent with the ability of cytochalasin D and latrunculin A to prevent long-term potentiation in the CA1 area of the hippocampus and dentate gyrus, respectively, without affecting basal synaptic transmission (Krucker et al., 2000; Fukazawa et al., 2003). It may be speculated that actin rearrangement affected both acquisition and extinction of context-dependent conditioned freezing by altering the function of NMDA receptors (Allison et al., 1998) that are required for acquisition as well as extinction of fear-potentiated startle (Miserendino et al., 1990; Falls et al., 1992). It is also possible that some of the recently described roles of the cAMP-dependent protein kinase and extracellular signal-regulated kinases in extinction of conditioned fear responses (Lu et al., 2001; Szapiro et al., 2003) may be mediated, at least in part, by their interactions with dynamic actin (Julien and Mushynski, 1998). Such effects remain 
to be delineated from the genomic actions of these kinases that might also contribute to extinction.

Taken together, in contrast to the robust involvement in the acquisition of conditioned responses, the role of protein synthesis in extinction appears to vary significantly depending on the conditioning and extinction paradigm. On the basis of the findings obtained in the present and previous studies, it appears that there are at least two different mechanisms involved in extinction of conditioned fear responses. One seems to depend on generation of new associations (Berman and Dudai, 2001; Vianna et al., 2001). The other mechanism that was detectable after short repeated extinction trials predominantly involved cytoskeletal rearrangement. In line with the possibility that such trials might preferentially activate the excitatory association (Eisenberg et al., 2003), mechanisms involving actin rearrangement could be predominantly elicited within the neuronal circuitry that enables the conditioning memory to trigger the freezing response. Importantly, such alterations could be reversed after a reminder that increases anew the synaptic strength in neurons storing the original memory. The delineation of different extinction mechanisms may enable the identification of individual neurons and circuits involved in the processing of memories acquired during conditioning and extinction and help to better understand the pathophysiological processes leading to impaired extinction of contextual memories, as observed in anxiety and addictive disorders.

\section{References}

Allison DW, Gelfand VI, Spector I, Craig AM (1998) Role of actin in anchoring postsynaptic receptors in cultured hippocampal neurons: differential attachment of NMDA versus AMPA receptors. J Neurosci 18:2423-2436.

Anokhin KV, Tiunova AA, Rose SP (2002) Reminder effects - reconsolidation or retrieval deficit? Pharmacological dissection with protein synthesis inhibitors following reminder for a passive-avoidance task in young chicks. Eur J Neurosci 15:1759-1765.

Antonova I, Arancio O, Trillat AC, Wang HG, Zablow L, Udo H, Kandel ER, Hawkins RD (2001) Rapid increase in clusters of presynaptic proteins at onset of long-lasting potentiation. Science 294:1547-1550.

Berman DE, Dudai Y (2001) Memory extinction, learning anew, and learning the new: dissociations in the molecular machinery of learning in cortex. Science 291:2417-2419.

Blanchard RJ, Blanchard DC (1969) Crouching as an index of fear. J Comp Physiol Psychol 67:370-375.

Bouton ME (1993) Context, time, and memory retrieval in the interference paradigms of Pavlovian learning. Psychol Bull 114:80-99.

Cahill L, NcGaugh JL, Weinberger NM (2001) The neurobiology of learning and memory: some reminders to reminder. Trends Neurosci 24:578 -581.

Davis HP, Squire LR (1984) Protein synthesis and memory: a review. Psychol Bull 96:518-559.

Debiec J, LeDoux JE, Nader K (2002) Cellular and systems reconsolidation in the hippocampus. Neuron 36:527-538.

Edwards DR, Mahadevan LC (1992) Protein synthesis inhibitors differentially superinduce c-fos and c-jun by three distinct mechanisms: lack of evidence for labile repressors. EMBO J 11:2415-2424.

Eisenberg M, Kobilo T, Berman DE, Dudai Y (2003) Stability of retrieved memory: inverse correlation with trace dominance. Science 301:1102-1104.

Falls WA, Davis M (1995) Behavioral and physiological analysis of fear inhibition. Extinction and conditioned inhibition. In: Neurobiological and clinical consequences of stress: from normal adaptation to PTSD (Friedman MJ, Charney DS, Deutch AJ, eds), pp 177-202. Philadelphia: Lippincott-Raven.

Falls WA, Miserendino MJ, Davis M (1992) Extinction of fear-potentiated startle: blockade by infusion of an NMDA antagonist into the amygdala. J Neurosci 12:854-863.

Fukazawa Y, Saitoh Y, Ozawa F, Ohta Y, Mizuno K, Inokuchi K (2003) Hippocampal LTP is accompanied by enhanced F-actin content within the dendritic spine that is essential for late LTP maintenance in vivo. Neuron 38:447-460.

Harris JA, Westbrook RF (1998) Benzodiazepine-induced amnesia in rats: reinstatement of conditioned performance by noxious stimulation on test. Behav Neurosci 112:183-192.

He Q, Dent EW, Meiri KF (1997) Modulation of actin filament behavior by GAP-43 (neuromodulin) is dependent on the phosphorylation status of serine 41, the protein kinase C site. J Neurosci 17:3515-3524.

Julien JP, Mushynski WE (1998) Neurofilaments in health and disease. Prog Nucleic Acid Res Mol Biol 61:1-23.

Kelly MP, Deadwyler SA (2002) Acquisition of a novel behavior induces higher levels of Arc mRNA than does overtrained performance. Neuroscience 110:617-626.

Kim JJ, Fanselow MS (1992) Modality-specific retrograde amnesia of fear. Science 256:675-677.

Konorski J (1948) Conditioned reflexes and neuronal organization. London: Cambridge UP.

Krucker T, Siggins GR, Halpain S (2000) Dynamic actin filaments are required for stable long-term potentiation (LTP) in area CAl of the hippocampus. Proc Natl Acad Sci USA 97:6856-6861.

Lattal KM, Abel T (2001) Different requirements for protein synthesis in acquisition and extinction of spatial preferences and context-evoked fear. J Neurosci 21:5773-5780.

Lin CH, Yeh SH, Lu HY, Gean PW (2003) The similarities and diversities of signal pathways leading to consolidation of conditioning and consolidation of extinction of fear memory. J Neurosci 23:8310-8317.

Lu KT, Walker DL, Davis M (2001) Mitogen-activated protein kinase cascade in the basolateral nucleus of amygdala is involved in extinction of fear-potentiated startle. J Neurosci 21:RC162(1-5).

Malkani S, Rosen JB (2000) Specific induction of early growth response gene 1 in the lateral nucleus of the amygdala following contextual fear conditioning in rats. Neuroscience 97:693-702.

Milekic MH, Alberini CM (2002) Temporally graded requirement for protein synthesis following memory reactivation. Neuron 36:521-525.

Millin PM, Moody EW, Riccio DC (2001) Interpretations of retrograde amnesia: old problems redux. Nat Rev Neurosci 2:68-70.

Miserendino MJ, Sananes CB, Melia KR, Davis M (1990) Blocking of acquisition but not expression of conditioned fear-potentiated startle by NMDA antagonists in the amygdala. Nature 345:716-718.

Myers KM, Davis M (2002) Systems-level reconsolidation: reengagement of the hippocampus with memory reactivation. Neuron 36:340-343.

Nader K, Schafe GE, Le Doux JE (2000) Fear memories require protein synthesis in the amygdala for reconsolidation after retrieval. Nature 406:722-726.

Osten P, Valsamis L, Harris A, Sacktor TC (1996) Protein synthesisdependent formation of protein kinase $\mathrm{M} \zeta$ in long-term potentiation. J Neurosci 16:2444-2451.

Pavlov IP (1927) Conditioned reflexes. Oxford: Oxford UP.

Pedreira ME, Maldonado H (2003) Protein synthesis subserves reconsolidation or extinction depending on reminder duration. Neuron 38:863-869.

Radulovic J, Kammermeier J, Spiess J (1998) Relationship between fos production and classical fear conditioning: effects of novelty, latent inhibition, and unconditioned stimulus preexposure. J Neurosci 18:7452-7461.

Rao A, Craig AM (2000) Signaling between the actin cytoskeleton and the postsynaptic density of dendritic spines. Hippocampus 10:527-541.

Rescorla RA, Heth CD (1975) Reinstatement of fear to an extinguished conditioned stimulus. J Exp Psychol Anim Behav Process 104:88-96.

Riccio DC, Richardson R (1984) The status of memory following experimentally induced amnesias: gone, but not forgotten. Physiol Psychol 12:59-72.

Szapiro G, Vianna MR, McGaugh JL, Medina JH, Izquierdo I (2003) The role of NMDA glutamate receptors, PKA, MAPK, and CAMKII in the hippocampus in extinction of conditioned fear. Hippocampus 13:53-58.

Torocsik B, Szeberenyi J (2000) Anisomycin affects both pro- and antiapoptotic mechanisms in PC12 cells. Biochem Biophys Res Commun 278:550-556.

Vianna MR, Szapiro G, McGaugh JL, Medina JH, Izquierdo I (2001) Retrieval of memory for fear-motivated training initiates extinction requiring protein synthesis in the rat hippocampus. Proc Natl Acad Sci USA 98:12251-12254. 